\title{
Calibration of GaAlAs Semiconductor Diode
}

\author{
S. B. Ota ${ }^{1}$, Smita Ota ${ }^{1,2}$ \\ ${ }^{1}$ Institute of Physics, Bhubaneswar, India \\ ${ }^{2}$ DST Project, DST, New Delhi, India \\ Email: snehadri@hotmail.com
}

Received July 29, 2012; revised September 1, 2012; accepted September 11, 2012

\begin{abstract}
The forward voltage of GaAlAs semiconductor diode has been measured in the temperature range $50 \mathrm{~K}-300 \mathrm{~K}$ and for current values between $10 \mathrm{nA}$ and $450 \mu \mathrm{A}$. The forward voltage as a function of temperature is least-squares fitted and the coefficients are given. The 1 st and 2 nd order least-squares fitting has high temperature root between $400 \mathrm{~K}$ and 950 $\mathrm{K}$. The presence of the high temperature root indicates that the fitted polynomials are of similar character. The high temperature root is found to increase for the least squares fitted polynomials corresponding to higher current values.
\end{abstract}

Keywords: Semiconductor; Temperature Sensors; GaAlAs

\section{Introduction}

GaAlAs semiconductor diodes have been used in the measurement of low temperatures in the presence of magnetic field. The measurement of low temperature using GaAlAs diodes is based on the usual observation that the voltage across the forward-biased diode increases with decrease in temperature [1-5]. The behavior of the diode has been understood in terms of conduction primarily by recombination-generation currents given by the theory of Shockley and coworkers [6]. Below about $50 \mathrm{~K}$, the forward voltage increases more rapidly as the temperature is reduced, which gives rise to a bend in the temperature dependence of forward voltage [7-9]. The diodes are generally calibrated with $10 \mu \mathrm{A}$ of forward current. The factors among others which decide the use of GaAlAs semiconductor diodes for the measurement of low temperature are sensitivity, linearity, stability, power dissipation and noise [10-16]. The GaAlAs diodes can possibly be used in the ultra low temperature range ( 0.05 $1 \mathrm{~K}$ ) by reducing the forward current to $\sim 10 \mathrm{nA}$. In certain possible applications of semiconductor diodes for temperature measurement, a high precision in the measurement of temperature is needed. Such situations include, the measurement of temperature drift curve in low temperature heat pulse calorimetry [17]. In this article we have studied the calibration of GaAlAs diode and report the coefficients for five decades of current values, $10 \mathrm{nA}$ to $450 \mu \mathrm{A}$ and in the temperature range $50 \mathrm{~K}-300 \mathrm{~K}$.

In this paper, we give the temperature dependence of forward voltage of GaAlAs diode for various current values between $10 \mathrm{nA}$ and $450 \mu \mathrm{A}$ and in the temperature range $50 \mathrm{~K}$ to $300 \mathrm{~K}$. The paper is organized as follows.
In the following Section 2, the experimental details are given. Section 3 gives the least-squares fittings. The paper concludes with the conclusions in Section 4.

\section{Experimental Details}

The measurements were carried out using a computer controlled four-probe setup built around a closed cycle refrigerator [18]. The diode in the $\mathrm{CU}$ package configuration is epoxied into a flat cylindrical disk and the sensor leads are thermally anchored to the same disk. The metal encapsulation of the diode was fixed to the sample space of the closed cycle helium refrigerator with 0.2 $\mathrm{mm}$ thick indium foil and a thin layer of Apiezon-N grease by clamping with an aluminum disk with screws using moderate pressure. The leads were further anchored at the sample space to minimize any thermoelectromotive force developed. The temperature of the sample site was controlled using a calibrated type-D silicon diode thermometer in conjunction with a Leybold model LTC60 temperature controller (Leybold AG, Germany). The setup is automated using GPIB-IEEE-488 interface and the control program is written in MSDOS GWBASIC. Measurements were carried out between $50 \mathrm{~K}-300$ $\mathrm{K}$, for forward current from $10 \mathrm{nA}$ to $450 \mu \mathrm{A}$. The temperature increment was $10 \mathrm{~K}$ and the current increment was in 11 equal logarithm interval. Each data point was obtained by averaging 50 reading. A constant current was provided to the GaAlAs diode from a Keithley (Keithley Instruments, USA) model 224/2243 programmable current source. The forward voltage was measured using a Keithley model 182 sensitive digital voltmeter. 


\section{Least Squares Fitting and Discussions}

The forward current $I_{f}$ is related to the forward voltage $V_{f}$ in a GaAs p-n junction, as follows:

$$
\mathrm{I}_{\mathrm{f}}=\exp \left(\mathrm{qV}_{\mathrm{f}} / \eta \mathrm{kT}\right)
$$

where $\mathrm{q}$ is the electronic charge, $\mathrm{k}$ is the Boltzmann constant, $\mathrm{T}$ is the temperature, and $\eta$ is the ideality factor $[19,20]$. Depending on the value of $\eta$, four operating regions have been defined: recombination, diffusion, high injection and series resistance regions. The Equation (1) gives rise to a linear temperature dependence of $V_{f}$, for a fixed value of current. However, for extended temperature range $(\sim 100 \mathrm{~K})$, there is significant deviation of linearity. Therefore, the semiconductor diode are generally calibrated with respect to standard and interpolation data is made. However, in some situations a lower order polynomial covering a large temperature range is needed. The least-squares fitting provides such a polynomial. First the temperature is determined using the calibrated voltage value of the GaAlAs diode for $10 \mu \mathrm{A}$ of current, which was provided by the manufacturer. The measured voltage as a function of temperature, for various current values, was then least-squares fitted to the following polynomials:

$$
\mathrm{V}=\sum_{\mathrm{i}=0}^{\mathrm{n}} \mathrm{a}_{\mathrm{i}} \mathrm{T}^{\mathrm{i}} ; \mathrm{n}=1-4
$$

For the 1st order least squares fitting, there are two coefficients, which are given in Table $\mathbf{1}$, for various values of current. The coefficient $a_{0}$ and $a_{1}$ are found to be positive and negative, respectively. The $R^{2}$ of the least squares fitting was nearly 1.00 . There is high temperature root $\mathrm{T}_{0}$, for the least squares fitting, which is found to increase as the corresponding values of the current is increased from $10 \mathrm{nA}$ to $450 \mu \mathrm{A}$. The $\mathrm{T}_{0}$ is $454.100 \mathrm{~K}$ and $949.350 \mathrm{~K}$ for $10 \mathrm{nA}$ and $450 \mu \mathrm{A}$, respectively. The presence of the high temperature root indicates that the fitted polynomials are of similar character. In case of 1 st order least squares fitting the coefficient $\mathrm{a}_{1}$, represents the average sensitivity of the diode, which is found to decrease with increase in current. $a_{1}$ varies from $-3.562 \times$ $10^{-3}$ to $-1.706 \times 10^{-3} \mathrm{~V} / \mathrm{K}$ as the current is increased from $10 \mathrm{nA}$ to $450 \mu \mathrm{A}$. The coefficients $\mathrm{a}_{0}$ represent the extrapolated voltage at zero temperature, which was nearly constant and have a value of $1.6 \mathrm{~V}$.

In case of the 2nd order least squares fitting, there are three coefficients, which are given in Table 2 . The coefficient $\mathrm{a}_{0}$ is found to be positive, whereas, the coefficients $a_{1}$ and $a_{2}$ are found to be negative. The $R^{2}$ of the least squares fitting was nearly 1.00 . It is seen from Table 2 that there is high temperature root $\mathrm{T}_{0}$ for all values of current. The $\mathrm{T}_{0}$ increased from $411.637 \mathrm{~K}$ to 790.460 $\mathrm{K}$ as the current is increased from $10 \mathrm{nA}$ to $450 \mu \mathrm{A}$. The presence of the high temperature root indicates that
Table 1. The 1st order least squares fitting of GaAlAs diode.

\begin{tabular}{ccccc}
\hline Current & $\mathrm{a}_{0}$ & $\mathrm{a}_{1}$ & $\mathrm{R}^{2}$ & $\mathrm{~T}_{0}(\mathrm{~K})$ \\
\hline $10 \mathrm{nA}$ & 1.61769 & $-3.56241 \times 10^{-3}$ & 1.00 & 454.100 \\
$30 \mathrm{nA}$ & 1.62027 & $-3.56578 \times 10^{-3}$ & 1.00 & 481.395 \\
$100 \mathrm{nA}$ & 1.62279 & $-3.15623 \times 10^{-3}$ & 0.99 & 514.155 \\
$300 \mathrm{nA}$ & 1.62340 & $-2.96112 \times 10^{-3}$ & 0.99 & 548.239 \\
$1 \mu \mathrm{A}$ & 1.62220 & $-2.74034 \times 10^{-3}$ & 0.99 & 591.970 \\
$3 \mu \mathrm{A}$ & 1.61955 & $-2.53210 \times 10^{-3}$ & 0.99 & 639.607 \\
$10 \mu \mathrm{A}$ & 1.61480 & $-2.29636 \times 10^{-3}$ & 0.99 & 703.200 \\
$30 \mu \mathrm{A}$ & 1.60964 & $-2.08137 \times 10^{-3}$ & 0.99 & 773.356 \\
$100 \mu \mathrm{A}$ & 1.60706 & $-1.87127 \times 10^{-3}$ & 0.99 & 858.807 \\
$300 \mu \mathrm{A}$ & 1.61385 & $-1.73685 \times 10^{-3}$ & 0.99 & 929.182 \\
$450 \mu \mathrm{A}$ & 1.61999 & $-1.70642 \times 10^{-3}$ & 0.99 & 949.350 \\
\hline
\end{tabular}

the fitted polynomials are of similar character. The coefficient $\mathrm{a}_{0}$ varies more compared to the 1 st order leastsquares fitting for different values of current. The coefficient $\mathrm{a}_{0}$ is nearly $1.5 \mathrm{~V}$, which lower compared to that in the case of 1st order. The minimum of the coefficient $a_{1}$ occurs for a current value of $30 \mu \mathrm{A}$. Here, the coefficient $\mathrm{a}_{2}$ represents the deviation from linearity. It is seen from Table 2 that, there is maximum deviation from linearity, for current of $10 \mu \mathrm{A}$. The reason for choosing the $50-$ $300 \mathrm{~K}$ range is that for low currents $(\sim 10 \mathrm{nA})$ the least squares fitting extends to $\sim 50 \mathrm{~K}$ without systematic deviation. Moreover, the I-V characteristic changes significantly below $50 \mathrm{~K}$.

In case of $3 \mathrm{rd}$ and 4 th order least-squares fitting (Tables 3 and 4) there were no high temperature roots for all current values. Therefore, we conclude that the fitted polynomials for different values of current are not of similar nature.

\section{Conclusions}

The forward voltage of GaAlAs semiconductor diode is measured at low temperatures. The data is obtained for current values between $10 \mathrm{nA}$ and $450 \mu \mathrm{A}$ and in the temperature range $50 \mathrm{~K}$ to $300 \mathrm{~K}$. The voltage as a function of temperature is least-squares fitted to polynomials. From the second order fitting it is found that there is maximum deviation from linearity, for current of $10 \mu \mathrm{A}$. There are high temperature roots for all current values, in case of 1 st and 2 nd order least-squares fittings.

There were no high temperature roots for all current values for 3rd and 4th order fitted polynomials.

Further study is being carried out on the $1 / \mathrm{f}$ noise which has been found to be current dependent. 
Table 2. The 2st order least squares fitting of GaAlAs diode.

\begin{tabular}{cccccc}
\hline Current & $\mathrm{a}_{0}$ & $\mathrm{a}_{1}$ & $\mathrm{a}_{2}$ & $\mathrm{R}^{2}$ & $\mathrm{~T}_{0}(\mathrm{~K})$ \\
\hline $10 \mathrm{nA}$ & 1.54101 & $-2.49623 \times 10^{-3}$ & $-3.03030 \times 10^{-6}$ & 1.00 & 411.637 \\
$30 \mathrm{nA}$ & 1.54291 & $-2.29010 \times 10^{-3}$ & $-3.05732 \times 10^{-6}$ & 1.00 & 428.549 \\
$100 \mathrm{nA}$ & 1.54063 & $-2.01391 \times 10^{-3}$ & $-3.24671 \times 10^{-6}$ & 1.00 & 445.308 \\
$300 \mathrm{nA}$ & 1.53514 & $-1.73395 \times 10^{-3}$ & $-3.48788 \times 10^{-6}$ & 1.00 & 459.896 \\
$1 \mu \mathrm{A}$ & 1.52699 & $-1.41643 \times 10^{-3}$ & $-3.76282 \times 10^{-6}$ & 1.00 & 476.041 \\
$3 \mu \mathrm{A}$ & 1.51931 & $-1.13836 \times 10^{-3}$ & $-3.96129 \times 10^{-6}$ & 1.00 & 492.070 \\
$10 \mu \mathrm{A}$ & 1.51420 & $-8.97665 \times 10^{-4}$ & $-3.97539 \times 10^{-6}$ & 1.00 & 514.505 \\
$30 \mu \mathrm{A}$ & 1.51854 & $-8.14531 \times 10^{-4}$ & $-3.60063 \times 10^{-6}$ & 1.00 & 546.084 \\
$100 \mu \mathrm{A}$ & 1.54048 & $-9.45485 \times 10^{-4}$ & $-2.63127 \times 10^{-6}$ & 1.00 & 606.295 \\
$300 \mu \mathrm{A}$ & 1.58091 & $-1.27878 \times 10^{-3}$ & $-1.30194 \times 10^{-6}$ & 0.99 & 715.318 \\
$450 \mu \mathrm{A}$ & 1.60155 & $-1.44998 \times 10^{-3}$ & $-7.28841 \times 10^{-7}$ & & 0.99 \\
\hline
\end{tabular}

Table 3. The 3rd order least squares fitting of GaAlAs diode.

\begin{tabular}{ccccccc}
\hline Current & $\mathrm{a}_{0}$ & $\mathrm{a}_{1}$ & $\mathrm{a}_{2}$ & $\mathrm{a}_{3}$ & $\mathrm{R}^{2}$ & $\mathrm{~T}_{0}(\mathrm{~K})$ \\
\hline $10 \mathrm{nA}$ & 1.49824 & $-1.52918 \times 10^{-3}$ & $-9.20392 \times 10^{-6}$ & $1.17004 \times 10^{-8}$ & 1.00 & 454.69 \\
$30 \mathrm{nA}$ & 1.48601 & $-1.00362 \times 10^{-3}$ & $-1.12708 \times 10^{-5}$ & $1.55664 \times 10^{-8}$ & 1.00 & 428.55 \\
$100 \mathrm{nA}$ & 1.47027 & $-4.22960 \times 10^{-4}$ & $-1.34033 \times 10^{-5}$ & $1.92490 \times 10^{-8}$ & 1.00 & - \\
$300 \mathrm{nA}$ & 1.45653 & $4.36255 \times 10^{-5}$ & $-1.48359 \times 10^{-5}$ & $2.15070 \times 10^{-8}$ & 1.00 & - \\
$1 \mu \mathrm{A}$ & 1.44679 & $3.97017 \times 10^{-4}$ & $-1.53398 \times 10^{-5}$ & $2.19409 \times 10^{-8}$ & 1.00 & - \\
$3 \mu \mathrm{A}$ & 1.44864 & $4.59626 \times 10^{-4}$ & $-1.41628 \times 10^{-5}$ & $1.93341 \times 10^{-8}$ & 1.00 & - \\
$10 \mu \mathrm{A}$ & 1.46903 & $1.23853 \times 10^{-4}$ & $-1.04967 \times 10^{-5}$ & $1.23594 \times 10^{-8}$ & 1.00 & - \\
$30 \mu \mathrm{A}$ & 1.50732 & $-5.60957 \times 10^{-4}$ & $-5.21944 \times 10^{-6}$ & $3.06799 \times 10^{-9}$ & 1.00 & 587.04 \\
$100 \mu \mathrm{A}$ & 1.57098 & $-1.63505 \times 10^{-3}$ & $1.77085 \times 10^{-6}$ & $-8.34299 \times 10^{-9}$ & 1.00 & 524.02 \\
$300 \mu \mathrm{A}$ & 1.65570 & $-2.96994 \times 10^{-3}$ & $9.49439 \times 10^{-6}$ & $-2.04614 \times 10^{-8}$ & 1.00 & 498.49 \\
$450 \mu \mathrm{A}$ & 1.69658 & $-3.59868 \times 10^{-3}$ & $1.29884 \times 10^{-5}$ & $-2.59971 \times 10^{-8}$ & 0.99 & 489.30 \\
\hline
\end{tabular}

Table 4. The 4th order least squares fitting of GaAlAs diode.

\begin{tabular}{|c|c|c|c|c|c|c|c|}
\hline Current & $\mathrm{a}_{0}$ & $\mathrm{a}_{1}$ & $\mathrm{a}_{2}$ & $a_{3}$ & $\mathrm{a}_{4}$ & $\mathrm{R}^{2}$ & $\mathrm{~T}_{0}(\mathrm{~K})$ \\
\hline $10 \mathrm{nA}$ & 1.42610 & $7.24218 \times 10^{-4}$ & $-3.23316 \times 10^{-5}$ & $1.06777 \times 10^{-7}$ & $-1.35152 \times 10^{-10}$ & 1.00 & 389.77 \\
\hline $30 \mathrm{nA}$ & 1.40344 & $1.57558 \times 10^{-3}$ & $-3.77412 \times 10^{-5}$ & $1.24385 \times 10^{-7}$ & $-1.54686 \times 10^{-10}$ & 1.00 & - \\
\hline $100 \mathrm{nA}$ & 1.38432 & $2.26200 \times 10^{-3}$ & $-4.09602 \times 10^{-5}$ & $1.32534 \times 10^{-7}$ & $-1.61035 \times 10^{-10}$ & 1.00 & 411.15 \\
\hline $300 \mathrm{nA}$ & 1.38030 & $2.42464 \times 10^{-3}$ & $-3.92733 \times 10^{-5}$ & $1.21968 \times 10^{-7}$ & $-1.42805 \times 10^{-10}$ & 1.00 & 427.38 \\
\hline $1 \mu \mathrm{A}$ & 1.39792 & $1.92366 \times 10^{-3}$ & $-3.10084 \times 10^{-5}$ & $8.63539 \times 10^{-8}$ & $-9.15631 \times 10^{-11}$ & 1.00 & 463.60 \\
\hline $3 \mu \mathrm{A}$ & 1.43889 & $7.64118 \times 10^{-4}$ & $-1.72879 \times 10^{-5}$ & $3.21814 \times 10^{-8}$ & $-1.82625 \times 10^{-11}$ & 1.00 & 792.82 \\
\hline $10 \mu \mathrm{A}$ & 1.50556 & $-1.01745 \times 10^{-3}$ & $1.21696 \times 10^{-6}$ & $-3.57950 \times 10^{-8}$ & $6.84515 \times 10^{-11}$ & 1.00 & - \\
\hline $30 \mu \mathrm{A}$ & 1.57724 & $-2.74504 \times 10^{-3}$ & $1.71968 \times 10^{-5}$ & $-8.90838 \times 10^{-8}$ & $1.30994 \times 10^{-10}$ & 1.00 & - \\
\hline $100 \mu \mathrm{A}$ & 1.67849 & $-4.99342 \times 10^{-3}$ & $3.62394 \times 10^{-5}$ & $-1.50041 \times 10^{-7}$ & $2.01425 \times 10^{-10}$ & 1.00 & - \\
\hline $300 \mu \mathrm{A}$ & 1.82753 & $-8.33737 \times 10^{-3}$ & $6.45827 \times 10^{-5}$ & $-2.46927 \times 10^{-7}$ & $3.21921 \times 10^{-10}$ & 1.00 & - \\
\hline $450 \mu \mathrm{A}$ & 1.90347 & $-1.00615 \times 10^{-2}$ & $7.93194 \times 10^{-5}$ & $-2.98681 \times 10^{-7}$ & $3.87620 \times 10^{-10}$ & 1.00 & - \\
\hline
\end{tabular}




\section{Acknowledgements}

The author is benefited from his visit to Europe in 1988-1992 for HTSC research, Xiamen, China during 1995 for statistical physics conference and New Orleans, USA during 2008 for APS March meeting. We acknowledge Dr. C. Iannicello and others of American Institute of Physics for providing access to the URL of AIP UniPHY.

\section{REFERENCES}

[1] H. Harris, "Concerning a Thermometer Made with SolidState Diodes," Scientific American, Vol. 204, No. 6, 1961, p. 192.

[2] A. G. McNamara, "Semiconductor Diodes and Transistors as Electrical Thermometers," Review of Scientific Instruments, Vol. 33, No. 3, 1962, pp. 330-333. doi:10.1063/1.1717834

[3] B. G. Cohen, W. B. Snow and A. R. Tretola, "GaAs p-n Junction Diodes for Wide Range Thermometry," Review of Scientific Instruments, Vol. 34, No. 10, 1963, pp. 10911093. doi:10.1063/1.1718140

[4] J. Unsworth and A. C. Rose-Innes, "Silicon p-n Junctions as Low Temperature Thermometers," Cryogenics, Vol. 6, No. 4, 1966, pp. 239-240.

doi:10.1016/0011-2275(66)90101-9

[5] G. K. White, "Experimental Techniques in Low-Temperature Physics," Clarendon Press, Oxford, 1979, p. 115.

[6] C. T. Saha, R. N. Noyce and W. Shockley, "Carrier Generation and Recombination in p-n Junctions and p-n Junction Characteristics," Proceedings of the IRE, Vol. 45, No. 9, 1957, pp. 1228-1243.

doi:10.1109/JRPROC.1957.278528

[7] S. B. Ota and S. Ota, "A Study of Forward Characteristics of a GaAlAs Temperature Sensor Diode," Measurement Science and Technology, Vol. 11, No. 6, 2000, p. 815. doi:10.1088/0957-0233/11/6/327

[8] S. B. Ota and S. Ota, "Thermometry between $10-300 \mathrm{~K}$ Using GaAlAs Diode," Modern Physics Letter B, Vol. 14, No. 11, 2000, p. 393. doi:10.1142/S0217984900000549

[9] S. B. Ota, J. Bascuňán and S. Ota, "Low Temperature Characteristic of GaAlAs TEmperature Sensor Diode," Modern Physics Letter B, Vol. 15, No. 9, 2001, p. 319.
doi:10.1142/S0217984901001744

[10] J. Verperk and P. Strnad, "Stability of Silicon Diodes as Temperature Sensors in the Range 4.2 - $273 \mathrm{~K}$," Cryogenics, Vol. 24, 1984, pp. 245-248.

[11] E. Gmelin and W. Heinke, "Cryostat for Spatial and Spectral Luminescence Experiments," Cryogenics, 1976, pp. 614-615.

[12] Yu. M. Shwarts, et al., "Radiation-Resistant Silicon Diode Temperature Sensors," Sensors and Actuators A: Physical, Vol. 97-98, 2002, pp. 271-279. doi:10.1016/S0924-4247(01)00874-3

[13] V. L. Borblik, et al., "About Manifestation of the Piezojunction Effect in Diode Temperature Sensors," Semi. Phys. Quantum Elec. Optoelec., Vol. 6, No. 1, 2003, pp. 97-101.

[14] V. N. Sokolov and Yu. M. Shwarts, "Effect of Nonuniform Doping Profile on Thermometric Performance of Diode Temperature Sensors," Semi. Phys. Quantum Elec. Optoelec., Vol. 5, No. 2, 2002, pp. 201-211.

[15] P. S. Iskrenovic and D. B. Mitic, “Assortment of Optimal Conditions for Running the Impulse Diode Thermometer," Review of Scientific Instruments, Vol. 65, No. 2, 1994, p. 477. doi:10.1063/1.1145160

[16] P. S. Iskrenovic, "Systematic Error of Diode Thermometer," Review of Scientific Instruments, Vol. 80, No. 8, 2009, Article ID: 084901. doi:10.1063/1.3202102

[17] E. Gmelin and K. Ripka, "A Simple Versatile Sample Holder of Low Heat Capacity for Adiabetic Calorimetry," Cryogenics, Vol. 21, No. 2, 1981, pp. 117-118. doi:10.1016/0011-2275(81)90061-8

[18] S. B. Ota and S. Ota, "On the Ideality Factor of the GaAlAs Semiconductor Diode below Knee Voltage," Modern Physics Letter B, Vol. 21, No. 19, 2007, p. 1235. doi:10.1142/S0217984907013602

[19] S. Yoshida, et al., "Microscopic Basis for the Mechanism of Carrier Dynamics in an Operating p-n Junction Examined by Using Light-Modulated Scanning Tunneling Spectroscopy," Physical Review Letters, Vol. 98, No. 2, 2007, Article ID: 26802. doi:10.1103/PhysRevLett.98.026802

[20] L. Kirkup, et al., "Effect of Injection Current on the Repeatability of Laser Diode Junction Voltage-Temperature Measurements," Journal of Applied Physics, Vol. 101, No. 2, 2007, Article ID: 23118. doi:10.1063/1.2427097 